\title{
MIGRATORY BEHAVIOR AND DIFFERENTIAL RESOURCE ALLOCATION BETWEEN WING AND TAIL FEATHERS IN A PASSERINE BIRD
}

\author{
IVÁn de la Hera, ${ }^{1}$ Javier Pérez-Tris, and José luis Tellería \\ Departamento de Zoología y Antropología Física, Facultad de Biología, Universidad Complutense de Madrid, 28040 Madrid, Spain
}

\begin{abstract}
AвSTRACT.-Temporal and energetic constraints associated with migration may compromise plumage quality and, ultimately, flight ability in migratory birds. As a consequence, migrants may invest more resources in parts of the plumage that are essential for long, sustained flight (such as the primary wing feathers) than in less important feather tracts. We used migratory and sedentary Blackcaps (Sylvia atricapilla) to analyze within- and between-individual variation in the mass and quality of wing and tail feathers. Migratory Blackcaps in both adult and juvenile plumage had lighter tail feathers than sedentary Blackcaps, but the primary feathers were of similar mass. Interestingly, the quality of primary and tail feathers (estimated from the mass of the feather in relation to its size) were positively correlated within individuals. However, migratory individuals had higher-quality primary feathers than sedentary individuals, given the quality of their tail feathers. Therefore, migratory Blackcaps appeared to preferentially allocate limited resources to primary feathers at the expense of the quality of the less important tail feathers. We suggest that this represents an adaptive mechanism to reduce the costs of migration constraints on plumage functionality. Received 6 August 2009, accepted 17 February 2010.
\end{abstract}

Keywords: avian life-histories, Blackcap, fledging period, molt-migration tradeoff, resource allocation, Sylvia atricapilla.

Comportamiento Migratorio y Asignación Diferencial de Recursos Entre Plumas del ala y de la Cola en un Ave Paseriforme

RESUMEN.-Las limitaciones temporales y energéticas asociadas con la migración pueden comprometer la calidad del plumaje y, en última instancia, la eficiencia del vuelo en las aves migratorias. En consecuencia, los migrantes pueden invertir más recursos en aquellas partes del plumaje que son esenciales para los vuelos sostenidos de larga duración (como las plumas primarias del ala), e invertir menos en aquellas partes del plumaje que son menos importantes. Se utilizaron individuos migratorios y sedentarios de la especie Sylvia atricapilla para analizar la variación, entre y dentro de individuos, en la masa y calidad de las plumas del ala y de la cola. Tanto en el plumaje adulto como en el juvenil, las aves migratorias mostraron plumas de la cola más ligeras que las sedentarias, pero las plumas primarias presentaron masa similar. Como hecho interesante, la calidad de las plumas primarias y de la cola (estimada a partir de la masa de las plumas corregida por su tamaño) se correlacionó positivamente dentro de los individuos. Sin embargo, a una calidad similar de las plumas de la cola, los individuos migratorios mostraron plumas primarias de mayor calidad que los sedentarios. Por lo tanto, los limitados recursos de las aves migratorias parecieron invertirse preferentemente en las plumas primarias a costa de la calidad de las menos importantes plumas de la cola. Se sugiere que este hecho puede representar un mecanismo adaptativo para reducir los costes de las limitaciones de la migración sobre la funcionalidad del plumaje.

Plumage QUALITY HAS important implications in key functions such as thermoregulation, flight performance, and social communication (Ginn and Melville 1983, Jenni and Winkler 1994). Feather structure-and, consequently, functionality-depends on the quantity of resources that birds can invest in feathers, which may be constrained by energetic tradeoffs with other events of the life cycle or by environmental conditions that limit access to food (Lindström et al. 1993, Jenni and Winkler 1994). For instance, adverse weather, food shortages, exposure to predators, and other transitory environmental perturbations during feather production can cause an incomplete development of some feather structures (fault bars) that compromises the functionality of plumage (Jenni and Winkler 1994, Jovani and Blas 2004, Serrano and Jovani 2005). Moreover, plumage quality can also be compromised by reproduction and other costly activities that compete with feather production for the limited resource budgets of birds. However, the consequences for feather quality of costly behavioral adaptations (such as migration) or variable developmental conditions of the plumage (molt vs. juvenile plumage development) have received little attention. 
Molt is a process of plumage production that involves the regular replacement of old feathers by new ones in birds (Ginn and Melville 1983). In temperate regions, adult molt commonly occurs during summer after breeding, when food resources are still abundant, to avoid the costly overlap of reproduction and molt within the annual cycle (Hemborg and Lundberg 1998). As a consequence, molt follows reproduction, and a prolonged breeding season may delay molt and reduce the time and energy available in summer for feather production. Such a circumstance may lead to a molt acceleration that entails detrimental consequences on feather structure and quality (Nilsson and Svensson 1996, Dawson et al. 2000, Dawson 2004).

Although reproduction has been suggested as a major contributor to variation in molt performance, similar costs of plumage have been suggested for migratory birds in relation to sedentary ones (Hall and Fransson 2000, Serra 2001, de la Hera et al. 2009b). Migration deeply influences the biology of birds because fitting two migratory journeys into the annual cycle causes reorganization of the use of energetic resources and time (Piersma et al. 2005, Hedenström 2008). Thus, in response to an early departure from summer territories toward their wintering grounds, migrants are forced to speed up many physiological processes, including molt (Bonier et al. 2007, de la Hera et al. 2009a). Such acceleration of molt increases the bird's energetic demand per unit of time, which could render it difficult to satisfy the resource requirements of simultaneously growing feathers. Moreover, migrants must meet other energetically challenging activities, such as premigratory fattening, that can directly compete with molting for the available resources (Lindström et al. 1994, Bonier et al. 2007). For instance, adult migratory Blackcaps (Sylvia atricapilla) molt faster but produce lighter tail feathers than sedentary individuals, which has been interpreted as a consequence of the aforementioned constraints associated with migration (de la Hera et al. 2009b).

Another main process of plumage production is the development of the first set of true feathers-juvenile plumage-during fledging. Strong selection for rapid development of plumage to avoid nest predation could minimize the importance of migration constraints in the production of juvenile plumage (Jenni and Winkler 1994). However, research has revealed that the fledging period is shorter in migratory than in sedentary species (Meiri and Yom-Tov 2004), which suggests that migration could have similar consequences for the quality of juvenile feathers, a hypothesis that has not been evaluated before.

An interesting corollary question that emerges from a discussion of the potential effects of migration on the structure and quality of adult and juvenile feathers is whether such costs of feather quality are equally extended to different feather tracts. Previous studies have reported that under transitory stressful conditions that reduce resource availability, both adult and juvenile birds preferentially allocate resources to the more functionally relevant feather tracts at the expense of less essential feathers (Jovani and Blas 2004, Serrano and Jovani 2005). Thus, wing feathers provide thrust and greatly contribute to lift during flapping flight, whereas tail feathers make a minor contribution to lift generation and are mainly involved in maneuverability (Videler 2005). Therefore, the quality of primaries would affect the efficiency of flight and is expected to have a larger effect on the fitness of migratory birds than the quality of tail feathers (Serrano and Jovani 2005). Such circumstance raises the question of whether birds faced with the constraints of migration distribute their limited resources differentially among types of feathers, a possibility that would be partially supported by the fact that migratory birds produce longer wings and shorter tails than their sedentary counterparts (with regard to Blackcaps, see Tellería and Carbonell 1999).

We analyzed the mass and quality of the remiges and rectrices of adult and juvenile Blackcaps in relation to migration and tested whether migratory and sedentary life histories promote different resource-allocation rules between feather tracts depending on their functional relevance. We specifically predicted that at both the population (migratory vs. sedentary) and individual levels, migratory Blackcaps would produce comparatively better primary feathers than sedentary Blackcaps, as a mechanism to minimize the costs of migration constraints on plumage functionality.

\section{Methods}

Study area and field methods.-We captured Blackcaps in the Campo de Gibraltar region of southern Spain $\left(36^{\circ} 01^{\prime} \mathrm{N}, 5^{\circ} 36^{\prime} \mathrm{W}\right)$. During winter, local sedentary Blackcaps share this area with migratory Blackcaps that breed farther north (Pérez-Tris and Tellería 2002). We mist netted birds in January and February of 2006 and 2007. We aged and sexed birds on the basis of plumage and eye color (Svensson 1992, Jenni and Winkler 1994). From each individual, we plucked one of the second outermost tail feathers (fifth rectrix) and one of the innermost primary wing feathers (first primary), which were stored in dry paper envelopes until laboratory analyses. Birds with replaced (i.e., grown to substitute an accidental loss; see Svensson 1992) or dirty feathers were excluded from the analyses, which rendered a final sample size of 283 (235 migratory and 48 sedentary Blackcaps).

We distinguished migratory from sedentary Blackcaps by taking advantage of the great morphological variation associated with migratory behavior in birds, which is particularly well documented in the Blackcap (Tellería and Carbonell 1999). For this, we used a discriminant function that combined the length of the eighth primary feather (longer in migrants), the length of the tail (shorter in migrants), and the difference between the primary distances 1 and 9 (distances from the tip of each primary feather to the wing tip; greater in migrants). This method correctly classifies a high percentage of Iberian-breeding Blackcaps as either migratory or sedentary (90\% of classifications correct; Pérez-Tris et al. 1999, de la Hera et al. 2007), because migrants have longer and more pointed wings and shorter tails than sedentary counterparts. This technique suggests that $\sim 5$ sedentary and $\sim 24$ migratory Blackcaps may have been assigned to the wrong group. However, most of the migratory Blackcaps that appear during winter in our study area come from northern and central Europe, where Blackcaps show particularly longer and more pointed wings, but similar tail lengths, compared with their Iberian counterparts (Cramp 1992, Fiedler 2005). Consequently, this suggests that only a small percentage of migratory Blackcaps were misclassified (de la Hera et al. 2007).

We also differentiated between adult and juvenile Blackcaps because adult and juvenile birds produce their plumage under different ecological and developmental conditions (Jenni and Winkler 1994), which is expected to affect the availability of resources for feather production and could interact with the migratory 
behavior of birds. In Blackcaps, the juvenile plumage develops during the nestling and fledgling periods (Jenni and Winkler 1994). Shortly after fledging, juveniles undergo a postjuvenile molt that replaces only the contour feathers and hardly ever involves the primary and tail flight feathers sampled in the present study (Shirihai et al. 2001). Therefore, virtually all first-year Blackcaps maintain the juvenile set of flight feathers until the second summer, when they shed all the plumage (juvenile flight feathers and postjuvenile body feathers) and replace it with the first adult plumage in a complete molt. This molt process is then repeated in every subsequent summer. Thus, juveniles must simultaneously invest energy in plumage and in structural development, whereas adults can allocate more resources to feather production because they have already completed body growth. Moreover, resource availability for molting adults depends on the ability of the individual to acquire food, whereas the resources available for juvenile feather development depend on the ability of parents to deliver food to the nest.

Feather measurements. - In the laboratory, we weighed the feathers using a Mettler Toledo AG-245 digital balance (resolution: $0.01 \mathrm{mg}$ ) to estimate the quantity of energetic resources each individual invested in synthesizing its feathers. To control for the variation in feather mass caused by the size of feathers, we also measured feather length from the base to the tip of the feather using a Mitutoyo 500 digital caliper (resolution: $0.01 \mathrm{~mm}$ ). Because of their elongated shape, length is a main component of feather size, but it does not account for variation in feather shape and width. For that reason, feathers were also scanned using a Hewlett Packard Scanjet 5P at 600 dots per inch, and feather areas were calculated with PHOTOSHOP CS2, version 9.0 (Adobe Systems, San Jose, California). To avoid bias, all feather measurements were made by I. de la Hera.

Statistical analyses.-We used the General Linear Models module of STATISTICA, version 6.1 (StatSoft, Tulsa, Oklahoma), to perform statistical analyses. We first explored the factors that affect the mass of tail and primary feathers. For such analyses, we included migratory behavior (migratory or sedentary), age (adult or juvenile), sex, and year (2006 or 2007) as fixed-effect factors, and feather length and feather area as covariates.

In addition, we used the residuals from a regression of feather mass against an estimate of feather size (obtained from principal component analyses [PCAs] that included the length and area of feathers) for each type of feather (tail and primary feathers) as proxies of feather quality. The latter residuals provide a size-independent measure of the structural complexity of feathers (de la Hera et al. 2009b). Thus, positive residuals (high-quality feathers) will show a wider rachis and a greater density of barbs than negative residuals (low-quality feathers), two feather traits that are positively correlated with important properties of feathers, such as bending stiffness or resistance to wear (Dawson et al. 2000). In order to reveal the existence of different resource-allocation rules during plumage growth between migratory and sedentary Blackcaps, we attempted to account for the possibility that feather quality could be significantly affected by individual variation in phenotypic quality or in the ability to acquire resources. We expected that an influence of individual quality would be expressed as a positive association between the quality of primary and tail feathers (van Noordwijk and de Jong 1986). Thus, individuals with access to more resources would produce better tail and primary feathers than birds with a limited budget. To control for this, we analyzed individual variation in the quality of primary feathers in relation to migratory behavior, age, sex, and year as fixed-effect factors, with the quality of tail feathers as a covariate. If migration favors higher investment of resources in wing than in tail feathers, we predicted that migratory Blackcaps would produce better-quality primary feathers than sedentary Blackcaps with a given quality of tail feathers.

\section{Results}

Feather length and area significantly affected variation in the mass of tail and primary feathers (Table 1). After controlling for these effects, sedentary Blackcaps had heavier tail feathers than migrants in both age classes, a pattern that did not occur for the

TABLE 1. Results of general linear models analyzing variation in mass of each type of feather (tail and primary) in relation to age (juvenile or adult), migratory behavior, sex, and year in Blackcaps captured in the Campo de Gibraltar region of southern Spain in 2006 and 2007. Three- and four-way interactions were not significant (all $P>0.355$ ) and are not shown.

\begin{tabular}{|c|c|c|c|c|c|c|}
\hline & \multicolumn{3}{|c|}{ Tail feather mass } & \multicolumn{3}{|c|}{ Primary feather mass } \\
\hline & $\beta$ & $F^{\mathrm{a}}$ & $P$ & $\beta$ & $F^{\mathrm{a}}$ & $P$ \\
\hline Feather length & 0.606 & 131.71 & $<0.001$ & 0.622 & 178.73 & $<0.001$ \\
\hline Feather area & 0.169 & 9.3 & 0.003 & 0.165 & 11.8 & $<0.001$ \\
\hline Year & - & 0.45 & 0.505 & - & 0.16 & 0.69 \\
\hline Sex & - & 1.62 & 0.204 & - & 1.31 & 0.253 \\
\hline Age & - & 2.3 & 0.131 & - & 5.28 & 0.022 \\
\hline Migratory behavior & - & 4.39 & 0.037 & - & 0.25 & 0.616 \\
\hline Year* sex & - & 0.48 & 0.489 & - & 0.13 & 0.716 \\
\hline Year* age & - & 1.06 & 0.305 & - & 0.7 & 0.404 \\
\hline Sex $*$ age & - & 3.47 & 0.064 & - & 0.29 & 0.585 \\
\hline Year* migratory behavior & - & 0.47 & 0.492 & - & 0.05 & 0.823 \\
\hline Sex * migratory behavior & - & 1.09 & 0.298 & - & 0.05 & 0.832 \\
\hline Age * migratory behavior & - & 0.04 & 0.834 & - & 0.34 & 0.563 \\
\hline
\end{tabular}

${ }^{\mathrm{a}} \mathrm{df}=1$ and 265 . 

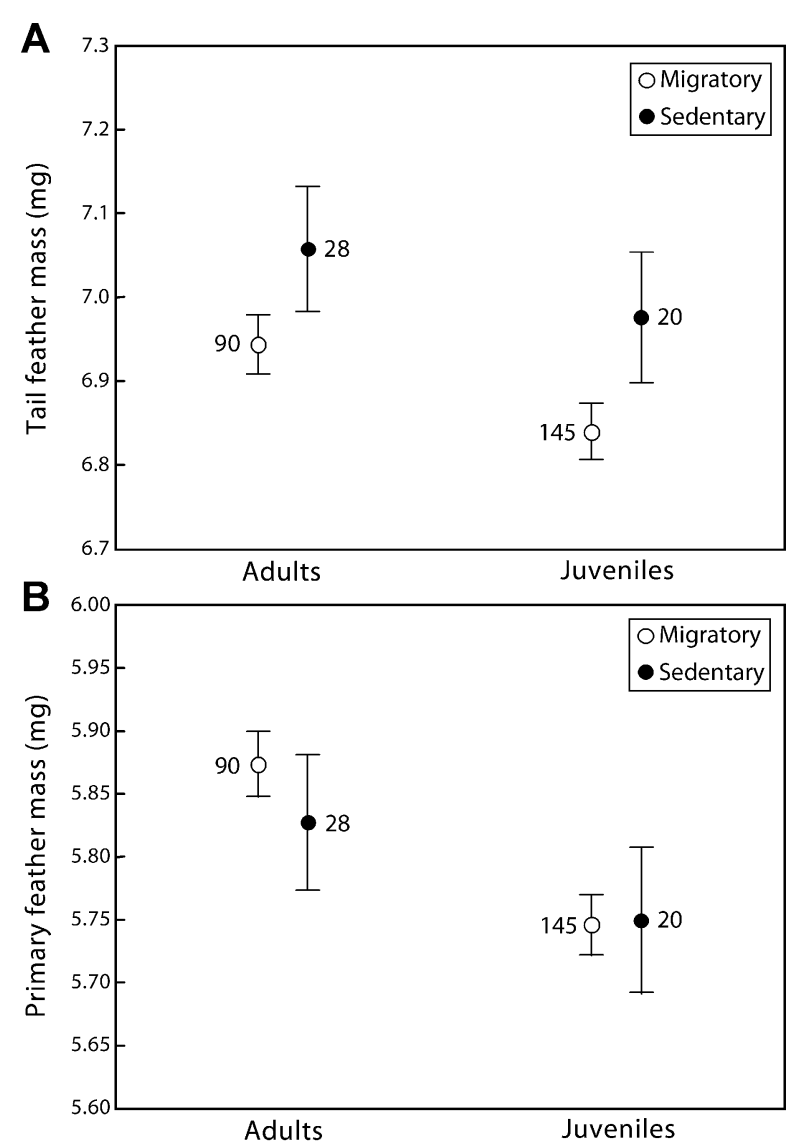

FIG. 1. Variation in the mass of (A) tail feathers and (B) primary feathers in relation to migratory behavior and age of Blackcaps captured in the Campo de Gibraltar region of southern Spain in 2006 and 2007. The graphs show means (adjusted by effects shown in Table 1), standard errors, and sample sizes.

mass of primary feathers: migratory and sedentary Blackcaps produced primary feathers of similar mass (Table 1 and Fig. 1). On the other hand, adult Blackcaps had heavier primary feathers than juveniles (Table 1 and Fig. 1) and tended to have heavier tail feathers, but the difference was not significant (Table 1).

The PCAs performed to estimate the size of feathers accounted for much of the variation in feather length and area in both tail (explained variance $=79 \%$; eigenvalue $=1.572$; factor loadings for length and area $=0.89)$ and primary feathers (explained variance $=$ $73 \%$; eigenvalue $=1.459$; factor loadings for length and area $=0.86$ ). Feather mass was significantly correlated with the factor 1 scores that were derived from the PCAs (tail feathers: $F=277.9, \mathrm{df}=1$ and $281, P<0.001, \beta=0.705$; primary feathers: $F=277.7, \mathrm{df}=1$ and 281 , $P<0.001, \beta=0.705)$. Using the residuals of these regression analyses as proxies of feather quality, we detected that Blackcaps with relatively high-quality tail feathers also had relatively high-quality primary feathers (as shown by a significant correlation between the two measures of feather quality; Table 2 and Fig. 2A). However, primary feathers were of comparatively higher quality in migratory Blackcaps than in sedentary ones (given the quality of tail feathers; Table 2 and Fig. 2B).
TABLE 2. Results of general linear models analyzing the quality of primary feathers (estimated as the residuals of feather mass on feather size) in relation to the quality of tail feather, age (juvenile or adult), migratory behavior, sex, and year in Blackcaps captured in the Campo de Gibraltar region of southern Spain in 2006 and 2007. Three- and four-way interactions were not significant (all $P>0.295$ ) and are not shown in the table.

\begin{tabular}{lccc}
\hline & $\beta$ & $F^{\mathrm{a}}$ & $P$ \\
\hline Tail feather quality & 0.592 & 140.61 & $<0.001$ \\
Year & & 1.16 & 0.282 \\
Sex & & 1.52 & 0.218 \\
Age & 2.58 & 0.11 \\
Migratory behavior & 6.9 & 0.009 \\
Year* sex & 0.05 & 0.828 \\
Year* age & 0.13 & 0.72 \\
Sex* age & 1.73 & 0.19 \\
Year* migratory behavior & & 0.14 & 0.713 \\
Sex* migratory behavior & 0.51 & 0.477 \\
Age* migratory behavior & & 0.3 & 0.585 \\
\hline
\end{tabular}

${ }^{\mathrm{a}} \mathrm{df}=1$ and 266 .
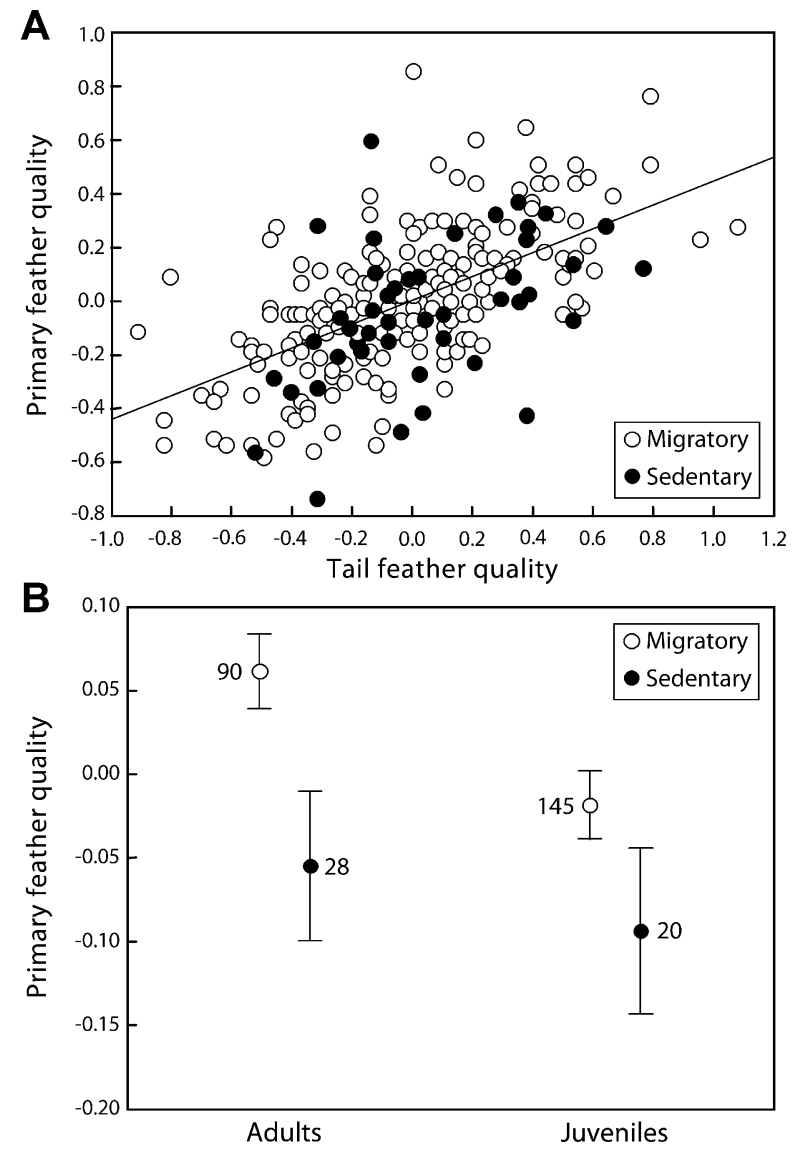

FIG. 2. (A) Relationship between the quality of primary and tail feathers in migratory and sedentary Blackcaps captured in the Campo de Gibraltar region of southern Spain in 2006 and 2007. (B) Variation between populations (migratory and sedentary) and age classes (adult and juvenile) in primary feather quality after controlling for the effects shown in Table 2. The graph shows means, standard errors, and sample sizes. 


\section{Discussion}

The quality of feathers depends greatly on their structural complexity (Dawson et al. 2000), which is essential for maintaining flight performance (Swaddle et al. 1996). For this reason, the resource-allocation rules between feather tracts during plumage production may greatly influence fitness, which may be particularly important for migratory individuals with demanding flight requirements (Serrano and Jovani 2005, Hedenström 2008). Our results suggest that migratory behavior affected the allocation of structural resources between two different types of feathers in Blackcaps. Migratory Blackcaps had lighter tail feathers than sedentary Blackcaps, but despite the reduced investment in tail feathers by migrants, primaries of the two groups were of equal feather mass.

Although other selective pressures could also contribute to the differences in feather quality between migratory and sedentary birds, the fact that migratory Blackcaps had lighter tail feathers has been interpreted as a cost of fast feather growth (Dawson et al. 2000, de la Hera et al. 2009a), because the duration of the molt of migrants is constrained by the penalty associated with overlapping molt and migration (Jenni and Winkler 1994, Norris et al. 2004). It has been reported that adult migratory Blackcaps molt their tail feathers faster than sedentary Blackcaps but produce relatively lighter feathers as a consequence (de la Hera et al. 2009b). The results presented here substantiate previous research and uncover the same pattern in the juvenile plumage. Therefore, although juvenile and adult plumages represent the outcome of different developmental processes (and are thus subjected to different physiological and ecological constraints; i.e., nestling somatic growth vs. reproduction), the effects of limitations associated with migration on feather formation are evident in both age classes, and plumage type (or age) does not influence the way in which migratory and sedentary individuals distribute resources between wing and tail feathers. This result is important for understanding the evolution of plumage characteristics of birds in relation to migration because it suggests that part of the cost associated with time constraints faced by the parents after the breeding season could be transferred to the offspring during the nesting period.

Interestingly, the mass of the primary feathers did not differ between migratory and sedentary populations, which is particularly relevant because migratory individuals invested relatively more resources in primary than in tail feathers. Thus, withinindividual relationships between the quality of primary feathers and that of tail feathers showed that migratory Blackcaps had relatively heavier (or higher-quality) primary feathers than sedentary Blackcaps. This result, together with the observed pattern of variation in the mass of primary and tail feathers between populations, suggests that migratory Blackcaps are making the best of a bad situation. By investing comparatively more in their primaries than in their tail feathers, migrants produced primary feathers of equal, but not better, quality than sedentary Blackcaps. Given that previous research has shown that migratory Blackcaps with light tail feathers also have high parasite loads (PérezTris et al. 2002), we conclude that migratory Blackcaps bear the cost of reduced tail-feather quality to maintain the quality of the primary feathers.
Positive within-individual correlations between tail and primary feather quality most likely reflect individual variation in phenotypic quality, mediated by the ability of individuals to acquire resources or by the different quality of the habitats that are occupied during summer (van Noordwijk and de Jong 1986, de la Hera et al. 2009b). Likewise, the fact that juvenile Blackcaps have lowerquality feathers than adults supports the view that differences in the ability of individuals to acquire resources may be a major source of variation in feather structure and quality. Juveniles produce all their feathers at once, and the amount of resources that they can allocate to feather production depends on the provisioning ability of their parents and the outcome of sibling competition (Trivers 1974).

Variable allocation of nutritional resources among different parts of the plumage and, more precisely, preferential investment in primary feathers, seems the rule rather than the exception among birds. For example, birds invest more resources in primary feathers under stressful conditions, and in doing so they reduce the quality of feathers of other feather tracts (Jovani and Blas 2004, Serrano and Jovani 2005). Likewise, feather ornaments have repeatedly evolved on birds' heads, inner wing feathers, or tails but hardly ever affect wing flight feathers (Balmford et al. 1993). The most immediate explanation for wing-quality conservatism in birds is that primary feathers have a greater functional significance than other feathers because primaries provide the necessary thrust for flapping flight (Videler 2005). Because the survival of migratory birds depends on their flight endurance, individual variation in the condition of primaries may represent a greater opportunity for natural selection in migrants.

\section{ACKNOWLEDGMENTS}

Our study was funded by the Spanish Ministry of Science and Technology (projects CGL2004-02744/BOS and CGL2007-62937/ BOS) and the Department of Education, Universities and Research of the Basque Government (BFI 04-33 and 09-13 studentships to I. de la Hera). We are particularly grateful to Á. Ramírez and M. Blázquez for their help during field work and to F. Pulido and two anonymous reviewers for their comments on drafts of the manuscript.

\section{Literature Cited}

Balmford, A., A. L. R. Thomas, And I. L. Jones. 1993. Aerodynamics and the evolution of long tails in birds. Nature 361: 628-631.

Bonier, F., P. R. Martin, J. P. Jensen, L. K. Butler, M. RamenofSKY, AND J. C. WINGFIELD. 2007. Pre-migratory life history stages of juvenile Arctic birds: Costs, constraints, and trade-offs. Ecology 88:2729-2735.

CRAmP, S., ED. 1992. Handbook of the Birds of Europe, the Middle East and North Africa: The Birds of the Western Palearctic, vol. 6: Warblers. Oxford University Press, Oxford, United Kingdom

DAwson, A. 2004. The effects of delaying the start of moult on the duration of moult, primary feather growth rates and feather mass in Common Starlings Sturnus vulgaris. Ibis 146:493-500.

Dawson, A., S. A. Hinsley, P. N. Ferns, R. H. Bonser, and L. ECCLESTON. 2000. Rate of moult affects feather quality: A mechanism linking current reproductive effort to future survival. 
Proceedings of the Royal Society of London, Series B 267:20932098.

de la Hera, I., J. A. Díaz, J. Pérez-Tris, and J. L. Tellería. 2009a. A comparative study of migratory behaviour and body mass as determinants of moult duration in passerines. Journal of Avian Biology 40:461-465.

de la Hera, I., J. Pérez-Tris, and J. L. Tellería. 2007. Testing the validity of discriminant function analyses based on bird morphology: The case of migratory and sedentary Blackcaps Sylvia atricapilla wintering in southern Iberia. Ardeola 54:81-91.

de la Hera, I., J. Pérez-Tris, And J. L. Tellería. 2009b. Migratory behaviour affects the trade-off between feather growth rate and feather quality in a passerine bird. Biological Journal of the Linnean Society 97:98-105.

FIEDLER, W. 2005. Ecomorphology of the external flight apparatus of Blackcaps (Sylvia atricapilla) with different migratory behavior. Annals of the New York Academy of Sciences 1046:253-263.

Ginn, H. B., AND D. S. Melville. 1983. Moult in Birds. British Trust for Ornithology, Tring, United Kingdom.

Hall, K. S. S., AND T. Fransson. 2000. Lesser Whitethroats under time-constraint moult more rapidly and grow shorter wing feathers. Journal of Avian Biology 31:583-587.

HeDENSTRÖM, A. 2008. Adaptations to migration in birds: Behavioural strategies, morphology and scaling effects. Philosophical Transactions of the Royal Society of London, Series B 363:287-299.

Hemborg, C., AND A. LundBERG. 1998. Costs of overlapping reproduction and moult in passerine birds: An experiment with the Pied Flycatcher. Behavioral Ecology and Sociobiology 43:19-23.

Jenni, L., AND R. WinKLER. 1994. Moult and Ageing of European Passerines. Academic Press, London.

Jovani, R., AND J. Blas. 2004. Adaptive allocation of stress-induced deformities on bird feathers. Journal of Evolutionary Biology 17:294-301.

Lindström, Å., S. DaAn, ANd G. H. Visser. 1994. The conflict between moult and migratory fat deposition: A photoperiodic experiment with Bluethroats. Animal Behaviour 48:1173-1181.

Lindström, Å., G. H. Visser, And S. DaAn. 1993. The energetic cost of feather synthesis is proportional to basal metabolic rate. Physiological Zoology 66:490-510.

MeIRI, S., AND Y. Yom-Tov. 2004. Ontogeny of large birds: Migrants do it faster. Condor 106:540-548.

Nilsson, J.-A.., AND E. Svensson. 1996. The cost of reproduction: A new link between current reproductive effort and future reproductive success. Proceedings of the Royal Society of London, Series B 263:711-714.
Norris, D. R., P. P. Marra, R. Montgomerie, T. K. Kyser, and L. M. RATCLIFFE. 2004. Reproductive effort, molting latitude, and feather color in a migratory songbird. Science 306:2249-2250.

Pérez-Tris, J., R. Carbonell, and J. L. Tellería. 1999. A method for differentiating between sedentary and migratory Blackcaps Sylvia atricapilla in wintering areas of southern Iberia. Bird Study 46:299-304.

Pérez-Tris, J., R. Carbonell, and J. L. Tellería. 2002. Parasites and the Blackcap's tail: Implications for the evolution of feather ornaments. Biological Journal of the Linnean Society 76:481-492.

Pérez-Tris, J., ANd J. L. Tellería. 2002. Migratory and sedentary Blackcaps in sympatric non-breeding grounds: Implications for the evolution of avian migration. Journal of Animal Ecology 71: 211-224.

Piersma, T., J. Pérez-Tris, H. Mouritsen, U. Bauchinger, and F. BAIRLEIN. 2005. Is there a "migratory syndrome" common to all migrant birds? Annals of the New York Academy of Sciences 1046:282-293.

SERRA, L. 2001. Duration of primary moult affects primary quality in Grey Plovers Pluvialis squatarola. Journal of Avian Biology 32: 377-380.

SerRano, D., and R. Jovani. 2005. Adaptive fault bar distribution in a long-distance migratory, aerial forager passerine? Biological Journal of the Linnean Society 85:455-461.

Shirihai, H., G. Gargallo, and A. J. Helbig. 2001. Sylvia Warblers: Identification, Taxonomy and Phylogeny of the Genus Sylvia. Princeton University Press, Princeton, New Jersey.

Svensson, L. 1992. Identification Guide to European Passerines, 4th ed. Published by the author, Stockholm.

Swaddle, J. P., M. S. Witter, I. C. Cuthill, A. Budden, And P. MCCow EN. 1996. Plumage condition affects flight performance in Common Starlings: Implications for developmental homeostasis, abrasion and moult. Journal of Avian Biology 27:103-111.

Tellería, J. L., AND R. CARbONELl. 1999. Morphometric variation of five Iberian Blackcap Sylvia atricapilla populations. Journal of Avian Biology 30:63-71.

Trivers, R. L. 1974. Parent-offspring conflict. American Zoologist 14:249-264.

VAN NOORDWIJK, A. J., AND G. DE JONG. 1986. Acquisition and allocation of resources: Their influence on variation in life history tactics. American Naturalist 128:137-142.

Videler, J. J. 2005. Avian Flight. Oxford University Press, Oxford, United Kingdom.

Associate Editor: M. T. Murphy 